\title{
Perioperative management of adult and pediatric sleep apnoea
}

\author{
Dipti Gothi*, Jyotsna M Joshi**
}

*Associate Professor, Department of Pulmonary Medicine, Era's Lucknow Medical College, Lucknow, India ** Professor, Department of Pulmonary Medicine, B.Y.L. Nair Hospital and T.N. Medical College, Mumbai, India

Indian J Sleep Med 2011; 6.2, 35-43

\begin{abstract}
Amongst the various diseases required to be screened preoperatively obstructive sleep apnoea $(O S A)$ is one of the most underdiagnosed conditions. The various screening tools devised to prevent OSA related postoperative complications are: Berlin questionnaire, STO P-BANG questionnaire, American Society of Anesthesiologist checklist and Perioperative Sleep Apnea Prediction Score. Among these, the STO P-BANG questionnaire is validated, sensitive, specific and viable and can even be self administered. Portable sleep study is the most practicable approach to confirm the diagnosis preoperatively in suspected cases. Continuous positive airway pressure (CPAP) administration is recommended for reducing the risk of complications related to OSA during post and or pre operative period although; the data describing the impact of CPAP therapy on adverse outcomes are limited. Also, close monitoring of patients postoperatively; a voiding use of sedatives and awake extubation are important components of postoperative care. Using CPAP in pre and or postoperative period can not only reduce the postoperative complication but also diagnose and sensitize the patients towards the long term management of OSA. The perioperative management of pediatric OSA is also similar to adult OSA, though clinically both are different.
\end{abstract}

Keywords: Excessive daytime sleepiness (EDS), obstructive sleep apnea (OSA), continuous positive airway pressure (CPAP), apnea hypopnea index (AHI)

\section{Introduction}

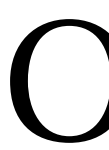

bstructive sleep apnea (OSA) needs to be recognized by anesthesiologist because it is not only more common in surgical patients than in the general population but also leads to increased perioperativemorbidity and mortality. ${ }^{1,2,3} \mathrm{G}$ uidelines have

\section{Address for correspondence}

\section{Prof. J MJoshi}

Head of Department of Pulmonary Medicine B.Y.L. Nair Hospital and T.N. Medical College, Dr A.L. Nair Road, Mumbai 400008, India Email: drjoshijm@gmail.com

Contact no: +91-022-23027642

Faxno: +91-022-23003095 been developed for identifying and managing the patients of OSA prior to surgery however it needs to be followed and pulmonologist are required work in tandem and guide the anesthesiologist so that more and more snorers are identified and prevented from the risk of going under the knife. ${ }^{4}$

\section{Prevalence of OSA in general population and preoperative patients}

It has been estimated that over $5 \%$ of middle aged adults and $24 \%$ adults above 65 years have OSA. 5,6,7 Eighty two percent cases of OSA remain undiagnosed. ${ }^{8}$ Prevalence of OSA in adult Indian population is reported to be approximately $3.5 \%$ i.e. 34 million people in India 
may be suffering from $O S A .{ }^{9} \mathrm{~A}$ recent study evaluating the prevalence of OSA in general surgical patients undergoing elective non-upper airway surgery has been estimated to be about $22 \% .{ }^{10}$ The study has also noted that $70 \%$ of patients were undiagnosed before presentation for perioperative evaluation. Another study has demonstrated prevalence of OSA in surgical population to be $3.2 \%{ }^{11} \mathrm{~T}$ hisstudy however had excluded patients undergoing cardiac surgery, in whom the risk of OSA is higher. Prevalence of OSA among obese bariatric surgery patients is more than $70 \%{ }^{12,13}$ Thus, though various studies have reported different prevalence of OSA in surgical populations, it appears that patients undergoing surgery have a higher prevalence of OSA.

\section{Postoperative complications due to OSA}

OSA has been shown to increase the need for intensive care intervention and prolongs the hospital stay. The complications usually occur during the first day after surgery, a small number may occur as late as postoperative days 4 and $5{ }^{14}$ The commonest complications are episodic hypoxemia and unplanned intensive care unit (ICU) transfer seen in about 33\% of patients with OSA. ${ }^{5,15}$ Serious complications like cardiac ischemia, respiratory failure and even death have been shown to occur in up to $24 \%$ of patients. ${ }^{5}$ The patients may even suffer from delirium. The complications during postoperative period related to OSA are summarized in table 1. ${ }^{16-23}$

\section{Pathophysiology of perioperative complications in OSA}

U pper airway collapse during sleep in OSA is due to the interplay of upper airway narrowing, abnormal muscle tone and genetic predisposition. ${ }^{14,} 24 \mathrm{U}$ pper airway narrowing, a key feature of OSA may lead to difficult intubation during intraoperative period. ${ }^{14} \mathrm{C}$ onsequences of OSA i.e. nocturnal hypoxemia, rapid eye movement (REM) sleep deprivation, and severe sleep fragmentation are believed to cause complications in the immediate and late postoperative period. ${ }^{14}$ (flow chart 1) Predictably, anesthetics abolish or blunt arousal from sleep, an important defense mechanism that occurs during natural sleep to overcome airway obstruction leading to prolonged hypoxemia. Anesthetic agents such as pentothal, propofol, opioids, benzodiazepines, and inhaled halogenated agents also reduce the tone of the
Table 1: PostoperativeC omplications R elated to OSA
Respiratory
- Difficult intubation
- Reintubation
- Acutehypercapnia
- Episodichypoxemia
- Atelectasis
- Pulmonary oedema
- Bronchospasm
- Laryngospasm
Cardiovascular
- Intraoperative hypertension
- Myocardial infarction
- Myocardial ischemia
- Arrhythmia
- H ypotension
Neurological
- Delirium
Miscellaneous
- GI bleeding
- Unanticipated admission to the ICU
- Sudden unexpected death
- Longer posanaesthesia recovery

pharyngeal musculature leading to increased propensity for upper airway collapse. ${ }^{25-29}$ These agents and opioids used for pain control also increase the risk of respiratory depression..$^{30}$ In a study assessing the ventilator response to carbon dioxide, apneic episodes were increased by up to $50 \%$ after modest doses of fentanyl $(0.5 \mu \mathrm{g} / \mathrm{kg})$. $^{31}$ REM rebound in the postoperative period due to OSA and disturbed sleep in hospital are known to compound respiratory and cardiovascular complications as most apneas and hypopneas occur in the REM stage. $\mathrm{N}$ eurological complication like delirium is also due to rebound of REM sleep. ${ }^{32}$

Flow chart 1: C onsequences of OSA

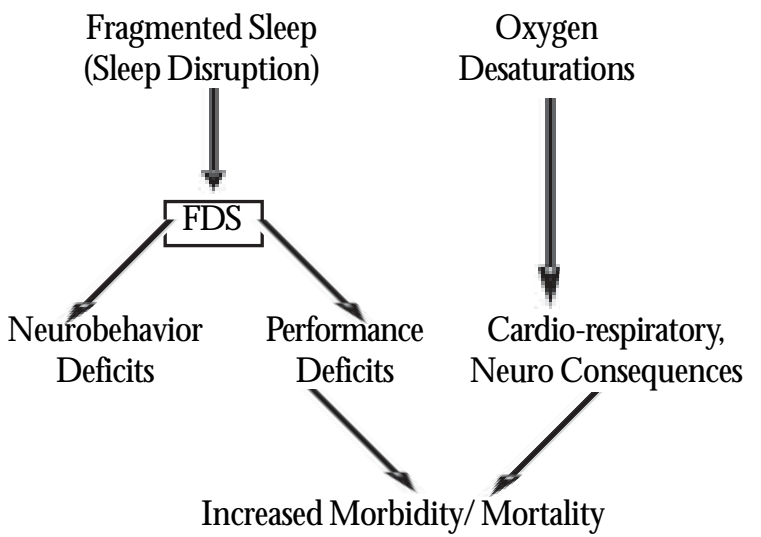




\section{Screening of OSA}

The various screening tools devised to detect the OSA cases at risk for post operative complications are: Berlin questionnaire ${ }^{33}$, ST OP-BAN G questionnaire ${ }^{34,35}$, American Society of Anesthesiologist (ASA) checklist ${ }^{4}$ and Perioperative Sleep A pnea Prediction Score (PSAP) ${ }^{36}$. The screening tools combine the risk factors, symptoms, signs and consequences of OSA. Since the screening is usually performed by the anesthesiologist the screening tool should be simple and non-time consuming keeping in mind the sensitivity and specificity. The comparison of the available tools is given in table 2 . The best screening tool is sensitive and specific yet easy to execute. The ST O P-BAN G questionnaire is validated, sensitive, specific and feasible and can be even be self administered. ${ }^{35}$ The scheme of perioperative evaluation and management if the questionnaire is positive is given in chart 2.

\section{Diagnosis of OSA}

$\mathrm{H}$ igh pretest probability on screening tools preoperatively is an indication for diagnostic evaluation. The diagnostic evaluation confirms OSA and helps in categorizing the severity of OSA for determining OSA scoring system (described in the next paragraph). The diagnosis of OSA and its severity is facilitated by the guidelines given in box $1 .{ }^{37}$ American Academy of Sleep M edicine has

Table 2 : Comparison of various questionnaires

\begin{tabular}{|c|c|c|c|c|}
\hline & Berlin questionnaire & $\begin{array}{l}\text { ST OP BAN G } \\
\text { Q uestionnaire }\end{array}$ & $\begin{array}{l}\text { American society of } \\
\text { anesthesiologist (ASA) } \\
\text { checklist }\end{array}$ & $\begin{array}{l}\text { Perioperative apnoea } \\
\text { prediction score (PAPS) }\end{array}$ \\
\hline $\begin{array}{l}\text { D evelopment of } \\
\text { screening tool }\end{array}$ & $\begin{array}{l}\text { D eveloped asscreening } \\
\text { tool for primary health } \\
\text { caresubsequently } \\
\text { validated for preoperative } \\
\text { evaluation }\end{array}$ & $\begin{array}{l}\text { Primarily developed for } \\
\text { preoperative evaluation } \\
\text { asSTO P, BAN G being } \\
\text { added subsequently }\end{array}$ & $\begin{array}{l}\text { Compiled list of } \\
\text { predisposing factors } \\
\text { and symptoms by } \\
\text { ASA }\end{array}$ & $\begin{array}{l}\text { Recently developed } \\
\text { tool specifically } \\
\text { for preoperative cases }\end{array}$ \\
\hline Q uestionnaire & $\begin{array}{l}3 \text { categories of questions } \\
\text { and category } 1 \text { and } 2 \\
\text { questionsareanswered } \\
\text { in } 2-5 \text { options. } \\
\text { C ategory 1-Snoring and } \\
\text { its detail, } \\
\text { C ategory 2- excessive } \\
\text { day timesleepiness, } \\
\text { Category 3-BP \& BM I. }\end{array}$ & $\begin{array}{l}\text { The following questions } \\
\text { are given to the patients, } \\
\text { the answers of which } \\
\text { arein yes and no } \\
\text { S- Snoring } \\
\text { T- Tiredness } \\
\text { O- O bserved apnoea } \\
\text { P- Blood pressure } \\
\text { B- BM I > 35 K g/m² } \\
\text { A- >50 years } \\
\mathrm{N}->40 \mathrm{~cm} \\
\mathrm{G}-\text { gender, male }\end{array}$ & $\begin{array}{l}3 \text { categories of } \\
\text { questionsand there } \\
\text { aremultiple questions } \\
\text { in each category } \\
\text { C ategory 1- } \\
\text { Predisposing factors } \\
\text { like, BM I, neck } \\
\text { circumference, } \\
\text { Category 2- history } \\
\text { suggestive of upper } \\
\text { airway obstruction } \\
\text { likesnoring, observed } \\
\text { apnoea } \\
\text { Category 3- history } \\
\text { suggestiveof excessive } \\
\text { day timesomnolence }\end{array}$ & $\begin{array}{l}3 \text { demographic } \\
\text { variables: age >43 } \\
\text { years, malegender, } \\
\text { and obesity; } \\
3 \text { history variables: } \\
\text { history of snoring, } \\
\text { type2 diabetes } \\
\text { mellitus, and } \\
\text { hypertension; } \\
3 \text { airway measures: } \\
\text { thick neck, modified } \\
\text { M allampati class3 or } \\
4, \text { and reduced } \\
\text { thyromental distance }\end{array}$ \\
\hline $\begin{array}{l}\text { Scoreindicating } \\
\text { high probability }\end{array}$ & $\begin{array}{l}\text { Two of the categories } \\
\text { should bepositive }\end{array}$ & $\geq 3$ yes & $\begin{array}{l}\text { Two of the categories } \\
\text { should bepositive }\end{array}$ & $\begin{array}{l}\text { The exact scorenot } \\
\text { yet being decided }\end{array}$ \\
\hline Feasibility & $\begin{array}{l}\text { M any variables } \\
\text { included with } \\
\text { complexity of } \\
\text { permutation } \\
\text { combination }\end{array}$ & $\begin{array}{l}\text { Easy to remember } \\
\text { and execute }\end{array}$ & $\begin{array}{l}\mathrm{N} \text { ot many variables } \\
\text { included but } \mathrm{C} \text { omplex } \\
\text { in its execution } \\
\text { because of permutation } \\
\text { combination }\end{array}$ & $\begin{array}{l}\text { Easy to remember and } \\
\text { execute }\end{array}$ \\
\hline Sensitivity & $>85 \%$ for severe O SA & $>90 \%$ & $>76 \%$ for severe O SA & Score $\geq 293 \%, \geq 623 \%$ \\
\hline Specificity & $46 \%$ & $63 \%$ & $36 \%$ & Score $\geq 232 \%, \geq 691 \%$ \\
\hline
\end{tabular}


Flow Chart 2: PreO perativeAssessment For Suspected O SA

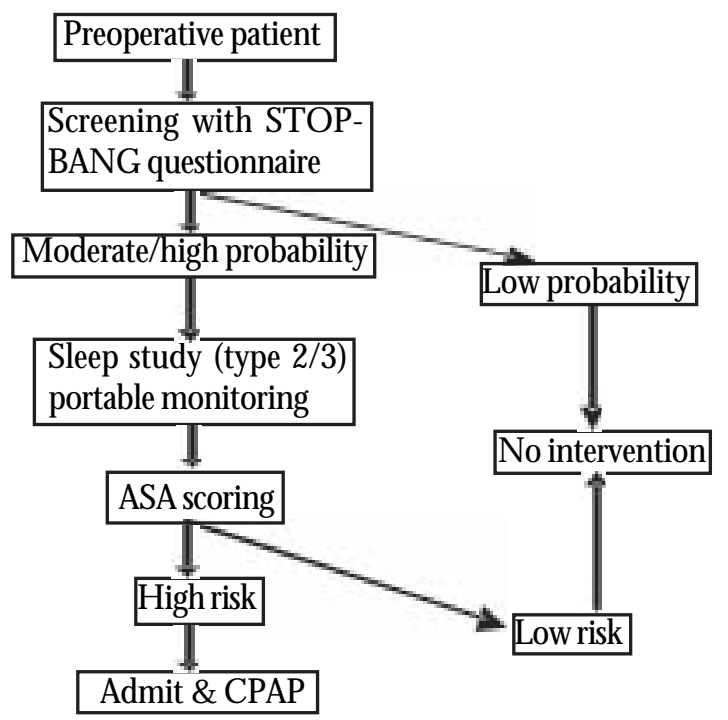

Box 1: D iagnostic Criteria and severity grading For OSA Diagnostic criteria

A. ED S* not better explained

B. 2 or $>$ of thefollowing not better explained Choking or gasping during sleep

Recurrent awakenings from sleep

U nrefreshing sleep

D aytimefatigue

Impaired concentration

C. PSG** showing $A \mathrm{II}^{* * *}>5$ in adults and $>1$ in children OSA must fulfill $A$ or $B$, pluscriterion $C$

\section{Severity G rading of OSA}

AHI/hour

Aduts

Mild:

5- 15

Children

2-4

M oderate: $15-30$

5-9

*ED S: Excessivedaytimeseepiness

**PSG : Polysonmography

***AH I: A pnoea hypopnoea index

classified the complexity of recording technology used for the diagnosis of sleep-related breathing disorders into type 1, 2, 3, 4. ${ }^{38}$ (box 2) The standard diagnostic test for OSA is an attended in-laboratory polysomnogram (PSG) that records physiologic variables, such as (EEG), electrocardiogram (ECG), chin and leg electromyograms, nasal and oral airflow, chest and abdominal efforts and pulse oximetry i.e. type 1 study. ${ }^{38} \mathrm{H}$ owever, recently
Box 2: Type of sleep study

N eurological
EEG
EOG
EM G
C ardio-Respiratory
ECG/heart rate
Snoring
Thoraco-abdominal movemen
Airflow
Oximetry

Type 1- standard polysomnography (PSG) with a minimum of 7 parameters measured i.e. EEG, EO G, chin EM G, and ECG , airflow, respiratory effort, and oxygen saturation.

Type 2 - comprehensive portable PSG (unattended) essentially sameas type 1, except that a heart ratemonitor can replacetheECG

Type3 - modified portable sleep apnea, (unattended) minimum of 4 parameters, including ventilation (at least two channels of respiratory movement, or respiratory movement and airflow), heart rate or ECG , and oxygen saturation

Type4 - continuous(singleor dual) bioparameter recording, measures a minimum of one parameter, usually oxygen saturation.

Note: A technician isin constant attendancein type 1 study; the other typesi.e. type 2, 3 and 4 areunattended

Portable M onitoring Task Force of the American Academy of Sleep M edicine has recommended that portable monitoring i.e. type 2 or 3 study (unattended) may be used as an alternative to PSG for the diagnosis of OSA in patients with a high pretest probability of moderate to severe OSA..$^{39}$ Though, type 4 devises have not been indicated for the diagnosis of OSA, a prospective randomized clinical trial by $D$ rummond and colleagues ${ }^{40}$ have found symptomatic improvement of daytime sleepiness and sleep-related quality of life with the initiation of empiric Auto-adjusting continuous positive airway pressure (Auto-PAP) therapy in patients with a high likelihood of having OSA while they were awaiting diagnostic laboratory-based PSG. Thus, depending of the availability of the diagnostic test and probability of OSA based on initial assessment the type of sleep study performed varies. Similarly, the diagnostic evaluation of OSA in preoperative cases may also vary. ${ }^{15} \mathrm{~T}$ he likelihood of delay in the surgery, the inconvenience, and the high cost of laboratory test makes home-based unattended portable screening devices with cardiorespiratory monitor (type 2 or 3) a preferred choice over type 1 study. ${ }^{3}$ 


\section{OSA Scoring system (box 3)}

Preoperatively diagnosed OSA should then be subjected to American Society of Anesthesiologists (ASA) scoring checklist for OSA. The scoring estimates the overall perioperative risk by combining (A) severity of OSA and $(B)$ invasiveness of the surgery or $(C)$ requirement of opioids. ${ }^{3}$ The severity of OSA is scored 1,2 and 3 if OSA is mild, moderate and severe respectively. $M$ ajor surgery or upper airway surgery under general anesthesia and high dose of opioid requirement are scored 3. The overall score is the score for $A$ plus the greater of the score for either B or C i.e. the maximum score is 6 . Patients with score of 4 may be at increased perioperative risk from OSA; patients with a score of 5 or 6 may be at significantly increased perioperative risk from OSA. O ne point may be subtracted if a patient has been on continuous positive airway pressure (CPAP) before surgery. $O$ ne point is added if a patient with has a resting arterial carbon dioxide tension $\left(\mathrm{PaC} \mathrm{O}_{2}\right)$ greater than 50 $\mathrm{mmH} \mathrm{g}$.

\section{Box 3: 0 SA scoring system}

\begin{tabular}{|l|}
\hline A. Severity of sleep apnoea \\
N one - 0 \\
M ild - 1 \\
M oderate - 2 \\
Severe - 3 \\
B. Invasiveness of surgery and anaesthesia \\
Superficial surgery/local anesthesia without sedation- 0 \\
Superficial surger/general anesthesia or moderatesedation- 1 \\
Peripheral surgery/ regional anaesthesia and moderate \\
sedation - 1 \\
Peripheral surgery/general anesthesia - 2 \\
Airway surgery/moderatesedation- 2 \\
M ajor surgery/ general anesthesia- 3 \\
Airway surgery/ general anaesthesia- 3 \\
C. Requirement of opioids \\
N one $0 \quad$ \\
Low- doseoral opioids- 1 \\
H igh - dose oral, parenteral, or neuraxial opioids- 3 \\
A+B or C (whichever ishighest amongst B/C) \\
$\quad=4$ increased risk of complications \\
$=5,6$ significantly increased risk \\
To deleteone point if the patient is on regular CPAP \\
To add one point if thereis associated hypoxia/ hypercarbia
\end{tabular}

\section{Perioperative management in cases of OSA to reduce the postoperative complication}

The perioperative management can be divided into preoperative, intraoperative and postoperative management.

\section{Preoperative management}

Preoperative evaluation consists of airway examination and identifying comorbidities such as hypertension, diabetes mellitus, and congestive heart failure. Patients who are diagnosed with OSA after PSG testing should be treated with preoperative CPAP, especially if OSA is severe. ${ }^{4,41}$ Although limited data ${ }^{4}$ support the routine preoperative use of CPAP, preoperative familiarization and adjustment to CPAP may be beneficial by increasing the likelihood of succesfful postoperative use. Patients who are already on CPAP therapy should continue to use the same settings.

\section{Intraoperative management}

Intraoperative concerns in patients at increased perioperative risk from OSA include (1) choice of anesthetic technique, (2) patient monitoring, and (3) airway management. ${ }^{4}$

Regional, spinal and epidural anesthesia is preferred over general anesthesia. General anaesthesia is preferred over deep sedation. ${ }^{42,43,44}$ If general anesthetic is given, shorter-acting agents that allow for a more rapid restoration of consciousness and a more rapid return to baseline respiratory function should be used. ${ }^{3}$ If sedation is essential ultra short acting opoids i.e. remifentanil is preferred drug of choice. ${ }^{3}$ D eep sedation is avoided at all cost while for moderate sedation, continuous monitoring preferably by capnography is recommended. ${ }^{4}$, ${ }^{43}$ CPAP should be used during sedation if the patient is previously treated with the same. ${ }^{4}$

Invasive arterial BP monitoring may be necessary if noninvasive BP monitoring is inaccurate or impossible because of associated morbid obesity. ${ }^{3}$ Preoxygenation with $100 \%$ oxygen and CPAP at $10 \mathrm{~cm} \mathrm{H}_{2} \mathrm{O}$ for 3 to 5 $\min$ in $25^{\circ}$ head-up position prior to general anaesthesia has been shown to be beneficial in predisposed individuals. 45,46 
OSA may also predispose to difficult tracheal intubation due to upper airway abnormalities especially in patients with greater M allampati score, anterior mandibular depth, and smaller mandibular and cervical angles. ${ }^{47,} 48,49,50$ Awake fiberoptic intubation may be required in such cases, one must however use topical anesthesia with caution during awake intubation as it further impairs upper airway protective reflexes. ${ }^{51,52}$ $D$ ifficult airway management guidelines should be followed whenever needed. ${ }^{53}$ The extubation should be carried out only when the patient is awake, after verifying reversal of neuromuscular block in non supine position. ${ }^{16}$

\section{Postoperative management}

U se of supplemental oxygen may increase the duration of apneic episodes and may hinder detection of atelectasis, transient apnea, and hypoventilation, thus providing only oxygen therapy during hypoxic event should be avoided. ${ }^{4}$ CPAP remains the most preferred therapy for OSA as it causes pneumatic splint and prevents upper airway collapse. ${ }^{54}$ CPAP or noninvasive positive-pressure ventilation (NIPPV), with or without supplemental oxygen, should be continuously administered when feasible to patients who were using these modalities preoperatively, unless contraindicated by the surgical procedure. ${ }^{4}$ In other patients with high risk of developing postoperative complication it is preferable to use CPAP postoperatively, however there are inadequate trials to confirm its use routinely. ${ }^{3,4} 0$ ne small study however has shown a reduction in postoperative complications in patients who used CPAP therapy preoperatively, on extubation, and nearly continuously for 24 to $48 \mathrm{~h}$ after surgery. ${ }^{55}$ If CPAP is not feasible, close pulse oximetry monitoring and a standby CPAP are obligatory. ${ }^{14}$ Auto-PAP devices present an attractive alternative in the perioperative setting when optimal CPAP settings may not be available or are difficult to determine. ${ }^{56}$ Alternatively CPAP pressure may be given based on body mass index (BMI) at 8, 10, 12 $\mathrm{cm} \mathrm{H} 20$ for $\mathrm{BM} \mathrm{I}<30 / \mathrm{Kg} \mathrm{m} 2,30-35 / \mathrm{Kg} \mathrm{m} 2$ and $\mathrm{BM} \mathrm{I}>35 / \mathrm{Kg} \mathrm{m} 2$ respectively ${ }^{57}$ It has been observed that the postoperative complications are low in patients with O SA on established home CPAP but are not put on CPAP postoperatively, ${ }^{15,58}$ possibly because of decreased inflammation or edema of the upper airway, decrease tongue size, as well as increased upper airway volume and stability.

It is preferable to keep the patient in non supine position postoperatively to reducetherisk of upper airway collapse. ${ }^{59}$ Continuousmonitoring should be maintained as long as patients remain at increased risk. U se of opioid analegesic is avoided for postoperative analgesia. Instead non steroid anti inflammatory drugs and analgesic adjuncts such as ketamine and dexmedetomidine which keep the respiratory drive intact with sedative and analgesic properties are preferred. ${ }^{60} \mathrm{~N}$ onopioid analgesics, local anaesthetics or when feasible, continuous regional anaesthesia using a catheter are useful alternative to opioids. ${ }^{43}$

It is recommended that during postoperative period the high risk patients should be observed for longer duration than those without OSA. Also, in addition to standard outpatient discharge criteria, room air oxygen saturation should return to its baseline and remain normal for a median of $7 \mathrm{~h}$ after the last episode of airway obstruction or hypoxemia while breathing room air in an unstimulating environment. ${ }^{4}$

\section{Preoperative evaluation of pediatric OSA}

Children with OSA are also at higher anesthetic risk in the perioperative period than those with normal upper airways. The rate of complications in children range from $6.4 \%$ to $27 \%$ depending on age, severity of OSA, uniformity of diagnosis, and comorbidities. ${ }^{61,62,63,64}$ ${ }^{65}$ Children $<3$ year of age are at twice the risk than 3-6 yr old children. ${ }^{65} \mathrm{C}$ omplications include oxygen desaturation $<90 \%$, increased work of breathing and changes on a chest radiograph (edema, atelectasis, infiltrate, pneumothorax, pneumomediastinum, or pleural effusion). ${ }^{66,67,68}$

Snoring as a screening tool is sensitive in $91 \%$ and specific in $75 \%$ of pediatric OSA. ${ }^{69}$ OSA otherwise presents differently in young children than it does in teenagers and adults. Adults and teenagers with OSA are often obese and have daytime somnolence; younger children may have normal weight or failure to thrive and behavior disorders such as hyperactivity, attention problems, and enuresis. ${ }^{70,71}$ Unlike adults the common predisposing factors for OSA in children are adenotonsillar hypetrophy and craniofacial abnormalities. D iagnostic criteria for polysomnography arealso different as cutoff for apnoea hypopnoea index in children is $1 /$ $\mathrm{hr} .{ }^{72} \mathrm{~T}$ he perioperative management strategies in children are however similar to adults. Children with very severe 
OSA who are at risk for persistent OSA and those with cardiovascular complications from OSA should be considered for preoperative CPAP/BiPAP therapy. ${ }^{73,74,}$ ${ }^{75}$ The other management strategies which apply to adult OSA are also important for managing pediatric OSA i.e. judicious use of opioids, close monitoring in the postoperative period and awake extubation.

To conclude, it is important to increase the awareness about postoperative complications due to OSA as it is one of the most underecognized conditions. Easy screening with a self administered questionnaire, evaluation by portable sleep study and optimal management during pre/intra/postoperative period will go a long way in preventing postoperative complications related to OSA.

\section{References}

1. Ogden C, Carroll MD, Curtin LR, McDowell MA, Tabak CJ, Flegal KM. Prevalence of overweight and obesity in the United States, 1999-2004. JAMA 2006; 295:1549-55.

2. Romero-Corral A, Caples SM, Lopez-Jimenez F, Somers VK. Interactions between obesity and obstructive sleep apnea:implications for treatment. Chest 2010;137:711-9.

3. Adesanya AO, Lee W, Greilich NB and Joshi GP. Perioperative Management of O bstructive Sleep Apnoea. Chest 2010;138;1489-98.

4. Gross JB, Bachenberg KL, Benumof J L, et al. Practice Guidelines for the Perioperative Management of Patients with Obstructive Sleep Apnea: Report by the American Society of Anesthesiologists Task Force on Perioperative Management of Patients with Obstructive Sleep Apnea. Anesthesiology 2006;104:1081-93.

5. Young T, Peppard PE, Gottlieb DJ. Epidemiology of obstructive sleep apnea: a population health perspective. Am J Respir Crit Care Med 2002;165:1217-39.

6. Ancoli-Israel S, Kripke DF, Klauber MR, Mason WJ, Fell R, Kaplan O. Sleep-disordered breathing in communitydwelling elderly. Sleep 1991;14:486-95.

7. Young T, Palta M, Dempsey J, Skatrud J, Weber S, Badr S. The occurrence of sleep-disordered breathing among middle-aged adults. N Engl J Med. 1993;328:1230-1235.

8. Kapur V, Strohl KP, Redline S, Iber C, O 'Connor G, N ieto J. Underdiagnosis of sleep apnea syndrome in U.S. communities. Sleep Breath 2002;6:49-54.

9. Saxena $\mathbf{S}$, Gothi D, Joshi JM. Prevalence of symptoms and risk of sleep disordered breathing in Mumbai (India). Indian J Sleep Med 2006;1.1:27-31.

10. Finkel KJ, Searleman AC, Tymkew H, et al. Prevalence of undiagnosed obstructive sleep apnea among adult surgical patients in an academic medical center. Sleep Med 2009;10:753-58.
11. Fidan H, Fatma F, Mehmet U, Yuksel E, Arif I, Levent T. Prevalence of sleep apnoea in patients undergoing operation. Sleep Breath 2006;10:161-5

12. Frey WC, Pilcher J. O bstructive sleep-related breathing disorders in patients evaluated for bariatric surgery. 0 bes Surg 2003;13:676-83.

13. Lopez PP, Stefan B, Schulman $\mathrm{Cl}$, et al. Prevalence of sleep apnea in morbidly obese patients who presented for weight loss surgery evaluation: more evidence for routine screening for obstructive sleep apnea before weight loss surgery Am Surg 2008;74: 834 -838.

14. Shafazand S. Perioperative management of obstructive sleep apnea: Ready for prime time? Cleveland Clinic J ournal Of Medicine 2009;76:S98- S103.

15. Gupta RM, Parvizi J, Hanssen AD, Gay P C. Postoperative Complications in Patients With Obstructive Sleep Apnea Syndrome Undergoing Hip or Knee Replacement: A CaseControl study. Mayo Clin Proc 2001;76:897-905.

16. Jain SS, Dhand R. Perioperative treatment of patients with obstructive sleep apnoea. Curr O pin Pulm Med. 2004;10:482-8.

17. Meoli AL, Rosen CL, Kristo D, et al. Clinical Practice review committee; American Academy of Sleep Medicine. Upper airway management of the adult patient with obstructive sleep apnoea in perioperative period - avoiding complications. Sleep 2003;26:1060-5.

18. Kaw R, Michota F, J affer A, et al. Unrecognized sleep apnea in the surgical patient: implications for the perioperative setting. Chest 2006;129:198-205.

19. Hwang D, Shakir N, Limann B, et al. Association of sleepdisordered breathing with postoperative complications. Chest 2008;133:1128-34.

20. Ostermeier AM, Raizen MF, Hautkappe M, Klock PA, Klafta JM. Three sudden postoperative respiratory arrest associated with epidural opioids in patients with sleep apnoea. Anesth Analg 1997;85:452-60.

21. Parikh SN, Stuchin SA, Maca C, Fallar E, Steiger D. Sleep apnea syndrome in patients undergoing total joint arthroplasty. J Arthroplasty 2002;17:635-42.

22. Reeder MK, Goldman MD, Loh L, et al. Postoperative obstructive sleep apneua. Haemodynamic effects of treatment with nasal CPAP. Anaesthesia 1991;46:849-53.

23. Reeder MK, Muir AD, Foex P, Goldman MD, Loh L, Smart D. postoperative myocardial ischemia temporal association with nocturnal hypoxaemia. Br J Anaesth 1991;67:626-31.

24. Marcus CL. Pathophysiology of childhood obstructive sleep apnea: current concepts. Respir Physiol 2000;119:143-54

25. Patil SP, Schneider H, Schwartz AR, Smith PL. Adult obstructive sleep apnea: pathophysiology and diagnosis. Chest 2007;132:325-37.

26. Isono S, Remmers JE, Tanaka A, Sho Y, Sato J, Nishino T. Anatomy of pharynx in patients with obstructive sleep apnea and in normal subjects. J Appl Physiol 1997;82:1319-26.

27. Sforza E, Petiau C, Weiss T, Thibault A, Krieger J. Pharyngeal critical pressure in patients with obstructive sleep apnea syndrome. Clinical implications. Am J Respir Crit Care Med.1999;159:149-57.

Indian Journal of Sleep M edicine (IJSM ), Vol. 6, N o. 2, 2011 
28. Younes $\mathbf{M}$. Contributions of upper airway mechanics and control mechanisms to severity of obstructive apnea. Am J Respir Crit Care Med 2003;168: 645-58.

29. Bachar G, Feinmesser R, Shpitzer T, Yaniv E, Nageris B, Eidelman L. Laryngeal and hypopharyngeal obstruction in sleep disordered breathing patients, evaluated by sleep endoscopy. Eur Arch O torhinolaryngol 2008;265:1397-1402.

30. Waters KA, McBrien F, Stewart P, Hinder M, Wharton S. Effects of O SA, inhalational anesthesia, and fentanyl on the airway and ventilation of children. J Appl Physiol 2002;92:1987-94

31. Strauss SG, Lynn AM, Bratton SL, Nespeca MK. Ventilatory response to $\mathrm{CO} 2$ in children with obstructive sleep apnea from adenotonsillar hypertrophy. Anesth Analg 1999;89:328-32.

32. Rosenberg J, Wildschiødtz G, Pedersen $M H$, von Jessen $F$ Kehlet $\mathrm{H}$. Late postoperative nocturnal episodic hypoxaemia and associated sleep pattern. BrJ Anaesth $1994 ; 72: 145$-50.

33. Chung F, Ward B, Ho J, Yuan H, Kayumov, Shapiro C Preoperative identification of sleep apnea risk in elective surgical patients, using the Berlin questionnaire. J Clin Anesth 2007;19:130-4

34. Chung F, Yegneswaran B, Liao P, et al. STO P questionnaire: a tool to screen patients for obstructive sleep apnea. Anesthesiology 2008;108:812-21.

35. Vasu TS, Doghramji K, Cavallazzi R, et al. O bstructive Sleep Apnea Syndrome and Postoperative Complications Clinica Use of the STOP-BANG Q uestionnaire. Arch O tolaryngol Head N eck Surg. 2010;136(10):1020-1024

36. Ramachandran SK, Kheterpal S, Consens F, et al Derivation and Validation of a Simple Perioperative Sleep Apnea Prediction Score Anesth Analg 2010;110:1007-15.

37. Chesson A, Ferber R, Fry J, et al. Practice parameters for the indications for polysomnography and related procedures. Polysomnography Task Force, American Sleep Disorders Association Standards of Practice Committee. Sleep. 1997;20:406-22.

38. Kushida CA, Littner MR, Morgenthaler T, et al. Practice Parameters for the Indications for Polysomnography and Related Procedures: An Update for 2005. Sleep 2005;28:499-520.

39. Collop NA, Anderson WM, Boehlecke B, et al. Clinical guidelines for the use of unattended portable monitors in the diagnosis of obstructive sleep apnea in adult patients. Portable Monitoring Task Force of the American Academy of Sleep Medicine.J Clin Sleep Med 2007;15:737-47.

40. Drummond F, Doelken P, Ahmed Q A, et al. Empiric autotitrating CPAP in people with suspected obstructive sleep apnea. J Clin Sleep Med. 2010;6:140-5.

41. Giles TL, Lasserson TJ, Smith BH, White J, Wright J, Cates C). Continuous positive airways pressure for obstructive sleep apnoea in adults. Cochrane Database Syst Rev 2006;3:CD001106 [Review]

42. Hillman DR, Loadsman JA, Platt PR, Eastwood PR O bstructive sleep apnoea and anaesthesia. Sleep Med Rev 2004;8:459-64.

43. Boushra NN. Anaesthetic management of patients with sleep apnoea syndrome. Can J Anaesth 1996; 43:599-616

44. Chung SA, Yuan H, Chung F. A systemic review of obstructive sleep apnea and its implications for anesthesiologists. Anesth Analg 2008;107:1543-63.

45. Delay J M, Sebbane M, Jung B, et al. The effectiveness of noninvasive positive pressure ventilation to enhance preoxygenation in morbidly obese patients: a randomized controlled study. Anesth Analg 2008;107:1707-13

46. Dixon BJ, Dixon JB, Carden JR, et al. Preoxygenation is more effective in the 25 degrees head-up position than in the supine position in severely obese patients: a randomized controlled study. Anesthesiology 2005;102:1110-5.

47. Hiremath AS, Hillman DR, James AL, et al. Relationship between difficult tracheal intubation and obstructive sleep apnoea. BrJ Anaesth 1998;80:606-11.

48. Benumof J L. O bstructive sleep apnea in the adult obese patient: implications for airway management. Anesthesiol Clin North America 2002:20:789-811.

49. Meoli AL, Rosen CL, Kristo D, et al. Upper airway management of the adult patient with obstructive sleep apnea in the perioperative period-avoiding complications. Sleep 2003;26:1060-5

50. Stierer $\mathbf{T L}$, Wright C, George A, et al. Risk assessment of obstructive sleep apnea in a population of patients undergoing ambulatory surgery. J Clin Sleep Med 2010;6:467-72

51. Deegan PC, Mulloy E, MCNicholas WT. Topica oropharyngeal anesthesia in patients with obstructive sleep apnea. Am J Respir Crit Care Med 1995;151:1108-1112.

52. Berry RB, Kouchi KG, Bower JL, Light RW. Effect of upper airway anesthesia on obstructive sleep apnea. Am J Respir Crit Care Med 1995;151:1857-1861.

53. Caplan RA, Benumof JL, Blitt CD, et al. American Society of Anesthesiologists Task Force on Difficult Airway Management: Practice Guidelines for Management of the Difficult Airway. Anesthesiology 2003;98:1269-77.

54. Sullivan CE, Issa FG, Berthon-J ones M, Eves L. Reversal of obstructive sleep apnoea by continuous positive airway pressure applied through the nares. Lancet 1981;1:862-865.

55. Rennotte MT, Baele P, Aubert G, Rodenstein DO. Nasal continuous positive airway pressure in the perioperative management of patients with obstructive sleep apnea submitted to surgery. Chest 1995;107:367-74.

56. West SD, J ones DR, Stradling JR. Comparison of 3 ways to determine and deliver pressure during nasal CPAP therapy for OSA. Thorax 2006;61:226-31.

57. Hukins CA. Arbitrary-pressure continuous positive airway pressure for OSAS. American Respiratory J ournal of Critica Care Medicine 2005;171:500-5

58. Hwang D, Shakir N, Limann B, et al. Association of sleep disordered breathing with postoperative complications. Chest 2008:133:1128-1134.

59. Lee $\mathbf{C H}$, Shin HW, Han DH. The implication of sleep position in the evaluation of surgical outcomes in obstructive sleep apnea. O tolaryngol Head Neck Surg 2009;140:531-5. 
60. Carollo DS, Nossaman BD, Ramadhyani U. Dexmedetomidine: a review of clinical applications. Curr O pin Anaesthesiol 2008;21:457-61.

61. Schechter MS. Section on Pediatric Pulmonology, Subcommittee on Obstructive Sleep Apnea Syndrome. Technical report: diagnosis and management of childhood obstructive sleep apnea syndrome. Pediatrics 2002;109:e69.

62. Rosen GM, Muckle RP, Mahowald MW, Goding GS, Ullevig C. Postoperative respiratory compromise in children with obstructive sleep apnea syndrome: can it be anticipated? Pediatrics 1994;93:784-8.

63. Brown KA, Laferriere A, Moss IR. Recurrent hypoxemia in young children with obstructive sleep apnea is associated with reduced opioid requirement for analgesia. Anesthesiology 2004;100:806-10.

64. Sanders JC, King MA, Mitchell RB, Kelly JP. Perioperative complications of adenotonsillectomy in children with obstructive sleep apnea syndrome. Anesth Analg 2006;103:1115-21.

65. Statham MM, Elluru RG, Buncher R, Kalra M. Adenotonsillectomy for obstructive sleep apnea syndrome in young children: prevalence of pulmonary complications. Arch Otolaryngol Head Neck Surg 2006;132:476-80.

66. Nixon GM, Kermack AS, McGregor CD, et al. Sleep and breathing on the first night after adenotonsillectomy for obstructive sleep apnea. Pediatr Pulmonol2005;39:332-8.

67. Brown KA, Morin I, Hickey C, Manoukian JJ, Nixon GM, Brouillette RT. Urgent adenotonsillectomy: an analysis of risk factors associated with postoperative respiratory morbidity. Anesthesiology 2003;99:586-95

68. Wilson K, Lakheeram I, Morielli A, Brouillette R, Brown K. Can assessment for obstructive sleep apnea help predict postadenotonsillectomy respiratory complications? Anesthesiology 2002;96:313-22.

69. Chau KW, Ng DK, Kwok CK, Chow PY, Ho JC. Clinical risk factors for obstructive sleep apnoea in children. Singapore Med J 2003;44:570-3.

70. Rosen CL. O bstructive sleep apnea syndrome in children: diagnostic challenges. Sleep 1996;19(suppl 10):S274-S7.

71. Marcus CL. Clinical and pathophysiological aspects of obstructive sleep apnea in children. Pediatr Pulmonol Suppl 1997;16:123-4.

72. Guilleminault $\mathbf{C}$ Lee $\boldsymbol{J}$, Chan A. Pediatric O bstructive Sleep Apnea Syndrome Arch Pediatr Adolesc Med. 2005;159:775-85.

73. Rennotte MT, Baele P, Aubert G, Rodenstein DO. Nasal continuous positive airway pressure in the perioperative management of patients with obstructive sleep apnea submitted to surgery. Chest1995;107:367-74.

74. Ryan CF, Lowe AA, Li D, Fleetham JA. Magnetic resonance imaging of the upper airway in obstructive sleep apnea before and after chronic nasal continuous positive airway pressure therapy. Am Rev Respir Dis 199;144:939-44.

75. Maraus CL, Ward SL, Mallory GB, etal. Use of nasal continuous positive airway pressure as treatment of childhood obstructive sleep apnea. J Pediatr1995;127:88-94. 